\title{
Prevalence of malaria and soil-transmitted helminth infections and their association with undernutrition in schoolchildren residing in Mfou health district in Cameroon
}

\author{
Viviane Hélène Matong Tchinda ${ }^{1 *}$, Roger Ponka ${ }^{2}$, Edward Sahfe Ndzi ${ }^{1}$, Arlette Kamdem \\ Madocgne $^{3}$, Motsebo Amédée ${ }^{1}$, Tchinda Mouafo Grâce ${ }^{1}$ and Roger Somo Moyou ${ }^{1}$ \\ ${ }^{1}$ The Medical Research Centre, Institute of Medical Research and Medicinal Plant Studies (IMPM), Ministry of Scientific \\ Research and Innovation, Yaoundé, Cameroon. \\ ${ }^{2}$ The Higher Institute of the Sahel, University of Maroua, Maroua, Cameroon. \\ ${ }^{3}$ Faculty of Medicine and Biomedical Sciences, University of Yaoundé I, Yaoundé, Cameroon.
}

Accepted 25 July, 2012

\begin{abstract}
Malaria and soil-transmitted helminths are common parasitic diseases found in school children in subSaharan Africa. We determined the prevalence and intensities of these infections in apparently healthy schoolchildren living in Mfou health district, where malaria and intestinal infections are among the first causes of morbidity. In a cross-sectional study involving 503 schoolchildren, anthropometric parameters were measured. Finger-prick blood and fresh stool samples were collected for malaria parasites determination, assessment of anaemia and detection of helminths' eggs. Logistic regression analysis was used to investigate the association between these infections and other factors. Overall, 40.6 and $29.6 \%$ of children harboured malaria parasites and worms respectively. Prevalences of mild, moderate and severe undernutrition were respectively $22.2,2.3$ and $0.5 \%$ for underweight, and $21.9,7.6$ and $2.0 \%$ for stunting. In logistic regression analysis, anaemia (OR=2.64, 95\% $\mathrm{Cl}: 1.71-4.07)$ and infection with Ascaris lumbricoides (OR=1.72, 95\% Cl: 1.01-2.91) were significantly associated with malaria infection. Infection with Trichuris trichiura was significantly associated with increased risks of underweight (OR=2.11, 95\% $\mathrm{Cl}: 1.11-4.01)$. Moreover, rural schoolchildren showed increased chances of carrying worms, compared to their urban counterparts (OR=2.60, $95 \% \mathrm{Cl}: \mathbf{1 . 7 5 - 3 . 8 6 ) . ~ M a l a r i a ~ p r e v e n t i o n ~}$ and school-based deworming activities should be re-enforced in Mfou health district to reduce the burden of these infections in children.
\end{abstract}

Key words: Malaria, soil-transmitted helminths, undernutrition, schoolchildren, Mfou, Cameroon.

\section{INTRODUCTION}

Malaria infection and soil-transmitted helminths (STHs) are among the most prevalent endemic parasitic diseases in sub-saharan Africa, where both diseases have similar geographical distribution and co-infections are common (Snow et al., 2005; Mwangi et al., 2006;

*Corresponding author. E-mail: vtchinda1@yahoo.com. Tel: 237 77543009 / 96809524.
Brooker et al., 2007; Brooker, 2010). In Cameroon, both infections are prevalent and responsible for increased morbidities and associated consequences in vulnerable populations, including young children, pregnant women and school-age children (Quakyi et al., 2000; Brooker et al., 2000; Kimbi et al., 2005a,b; Tchuem and N'Goran, 2009; Leke et al., 2010). Schoolchildren living in an environment with inadequate sanitation (Ziegelbauer et al., 2012), usually in deprived communities in rural areas, are likely to be infected with at least one of the three main 
STHs (Ascaris lumbricoides, Trichuris trichiura and hookworms [Ancylostoma duodenale and Necator americanus]), as well as other helminths species (Tchuem et al., 2003; Bethony et al., 2006; Mupfasoni et al., 2009; Ayalew et al., 2011). Infections by intestinal helminths have been shown to result in abdominal pain, diarrhea, anaemia, malnutrition, ulcers, intellectual retardation, cognitive and educational deficits, intestinal obstruction and, in severe chronic and untreated infections, could even lead to death (Crampton and Nesheim, 2002; Hotez et al., 2008; Hall et al., 2008; Brooker et al., 2010). In the context of continuous exposure to Anopheles mosquitoes, these conditions are further exacerbated with asymptomatic malaria parasites, often resulting in co-infections with Plasmodium, and thus, putting these children at enhanced risk of clinical disease (Mwangi et al., 2006; Nkuo-Akenji et al., 2006; Achidi et al., 2008).

Current preventive strategies adopted by the Ministry of Public Health for malaria in Cameroon are based on the use of insecticide-treated nets in households and intermittent preventive treatment with sulphadoxinepyrimethamine for pregnant women (Ministry of health/National Malaria Control Programme, 2011). On the other hand, activities aiming at reducing the burden of helminths infections in children are based on annual distribution of anthelminthics in primary schools (Tchuem and N'Goran, 2009), as well as other deworming activities which are integrated to immunization in preschool children (1-5 years) within the community.

Regular update on the prevalence and intensities of these infections are important in order to assess the impact of these control interventions on the burden of the infections, especially in children. However, there is currently a scarcity of such information in Mfou health district where malaria and intestinal infections are ranked respectively among the first and third cause of morbidities within this rural district. Therefore, our study was designed to determine the prevalences of malaria and STHs and their association with undernutrition in primary schoolchildren residing in this study locality.

\section{MATERIALS AND METHODS}

\section{Study area}

The study was conducted in 4 primary schools of Mfou health district, a forest area located in the Mefou and Afamba division, in the centre region of Cameroon. Two of the schools were situated in the district headquarter (Mfou urban), an emerging semi-urban area located at $\sim 25 \mathrm{~km}$ of Yaoundé, the Capital of Cameroon; while the two others were found in the rural area (Mfou rural). The population of the district was over 71000 inhabitants, who were mainly farmers (District Health Management Team, 2011). Most households in Mfou urban and nearly all in the rural area have no access to potable water and appropriate sanitation, but the socio-economic conditions are relatively improved in Mfou urban. Mfou is hyperendemic for malaria; transmission occurs all year round, with peaks during the rainy season and transition to the dry season.
Malaria morbidity ranked the first position among the top ten causes of morbidity in the district, while intestinal infections ranked the third position (District Health Management Team, 2011).

\section{Study population}

The study involved apparently healthy primary schoolchildren of both sexes aged between 3 and 16 years. This population also included children from the nursery section of one of the rural primary schools. Each participant was clinically examined for febrile symptoms (fever) or any other clinical conditions (headache, abdominal discomforts, etc.). Sick children were referred to Mfou district hospital for appropriate management.

Anthropometric measurements and assessment of
undernutrition

The age, sex, height and weight of children were measured to determine their anthropometric indices. Age of each child was obtained from school records, while weight was measured to the nearest $100 \mathrm{~g}$ using an electronic personal scale (Geepas ${ }^{\circledR}$ ). Height was measured to the nearest $1 \mathrm{~mm}$, using a height measuring board (Innotech International, 7-9 avenue F.V. Raspail-94110France). Weight-for-age Z-score (WAZ) and height-for-age Z-score (HAZ) were calculated to assess underweight and stunting status respectively, as indicators of undernutrition. WAZ is easily available and can capture both stunting, associated with long-term undernutrition and wasting, a manifestation of recent and acute undernutrition (Caulfield et al., 2004). These calculations took into account children' weight and height, as well as the median weight and height of healthy children of the same age and sex (WHO, 1983). WAZ and HAZ scores were classified as mild (-1.01 to -2.00 Standard Deviation [SD]); moderate $(-2.01$ to $-3 S D)$ or severe $(<-$ 3SD) undernutrition, and normal (WAZ $\geq-1 S D$ ) (Caulfield et al., 2004; Crookston et al., 2010; Mfonkeu et al., 2010).

\section{Sample collection and laboratory analyses}

Finger prick blood samples were collected directly onto a clean glass slide to prepare thick and thin blood films. Heparinised micro capillary blood was collected at the same time for assessment of anaemia. Additionally, fresh stool samples were collected from each child, in a clean plastic container. The samples were immediately transported in the laboratory for processing and analysis.

For malaria parasite detection, thin blood films were first fixed in methanol, stained with $50 \%$ May-Grunwald, and both thin and thick films were stained with $10 \%$ Giemsa stain. Slides were examined under a microscope (x100 objective). A slide was considered negative if malaria parasites were not detected after examination of 200-oil immersion fields of thick smear. For positive samples, the number of parasites per 200 white blood cells (WBCs) was counted and the parasite density estimated based on an average of 8000 WBCs/ $\mu \mathrm{l}$ of blood. All slides were read independently by two microscopists, and when discrepancy occurred, the slide was read by a third person. Plasmodium species was determined in thin films. Children with malaria parasites were treated with a fixed combination of Arthemether-Lumefantrine for three consecutive days, as recommended as one of the first line treatment for uncomplicated malaria in Cameroon.

For assessment of anaemia, heparinised micro capillary tubes containing fresh blood were centrifuged at $15,000 \mathrm{rpm}$ for $5 \mathrm{~min}$ (IEC Micro-MB centrifuge). The parked cell volume or hematocrit level was determined using a micro hematocrit reader. Anaemia was defined as hematocrit level $<33 \%$ (Quakyi et al., 2000).

Fresh stool samples were immediately processed using the Kato- 
Katz thick smear method. Two slides were prepared per child, kept refrigerated overnight and egg-counts were performed within 15-24 $\mathrm{h}$ after slides preparation. The number of eggs counted in $41.7 \mathrm{mg}$ of faeces was extrapolated as eggs per gram (epg) of faeces. Infected children were treated with a standard oral dose of Mebendazole, $2 \times 100 \mathrm{mg}$ per day for three consecutive days.

\section{Statistical analysis}

All statistical analyses were performed using SPSS version 18.0 and threshold for statistical significance was set at $p<0.05$. Overall descriptive statistics were carried out to select variables for consideration in multivariate regression models, using malaria infection or helminths status as dependent variable. Independent variables that were significant at $p<0.10$ were included in the models.

\section{Ethical considerations}

The study was approved by the National Ethics Committee of Cameroon. Participation was dependent on a written consent given by the parents/guardian of the children.

\section{RESULTS}

\section{Description of the study population}

A total of 503 children participated in the study which included 269 (53.5\%) males and 234 (46.5\%) females. About $55.5 \%$ resided in the urban area of Mfou, while $44.5 \%$ lived in the rural area. Age ranged from 3 to 16 years, with a mean of $8.4 \pm 2.7$ years. Children from urban Mfou were significantly younger (mean age $=7.9 \pm 2.0$ years; $p=0.001$ ) than their rural counterparts (mean age $=9.1 \pm 3.3$ years). A total of 40 children $(8.0 \%)$ were feverish (axillary temperature $>37.5^{\circ} \mathrm{C}$ ) at the time of the survey and the prevalence of fever was significantly elevated in children residing in Mfou urban (22.2\%; $\mathrm{p}=0.024)$, compared to those from Mfou rural (17.8\%).

\section{Prevalence of malnutrition and anaemia in the study children}

Table 1 shows the prevalence of the different categories of undernutrition according to WAZ and HAZ scores' classification, as well as in relation to the sex of children. Overall, mild undernutrition (-1.01 $\leq Z$-score $\geq-2 S D)$ was more prevalent in these children, while the prevalences of moderate $(-2.01 \leq Z$-scores $\geq-3 S D)$ and severe (Z-scores<3SD) undernutrition were relatively low. Children residing in the rural area had significant increased chances of being underweight compared to their urban counterparts (OR=1.63, 95\% Cl: 1.02-2.61; $p=0.040$ ). Likewise, male schoolchildren relative to females, showed increased chances of been underweight $(\mathrm{OR}=1.66,95 \% \mathrm{Cl}$ : $1.04-$ $2.66 ; \mathrm{p}=0.033)$. There was a significant age-related increase in the prevalence of underweight $(p=0.041)$.
Similarly, rural schoolchildren had more than two-fold increased chances of being stunted than those living in urban Mfou (OR=2.33, 95\% Cl: 1.59-3.42; $\mathrm{p}=0.000$ ). Also, male schoolchildren showed increased chances of been stunted compared to females (OR=1.59, 95\% Cl: 1.09-2.34; $p=0.016)$. There was no significant agerelated change in the prevalence of stunting $(p=0.210)$. The overall prevalence of anaemia was $33.5 \%$ (168 children) and there was no significant difference between the proportion of anaemic children residing in the rural area $(33 \%, n=74)$ and that from urban Mfou $(33.6 \%$, $\mathrm{n}=94)$. Likewise, no significant difference was observed in the prevalence of anaemia between male and female schoolchildren. However, there was a significant agerelated decrease $(\mathrm{p}=0.000)$ in the prevalence of anaemia; ranging from 66.7 to $37.7 \%$ and $17.3 \%$, respectively in under 5, 5-9 and 10-16 years old children. Additionally, children with mild to severe underweight showed increased prevalence of anaemia (43.3\%) compared to healthy ones $(36.7 \%)$, but the difference was not statistically significant $(p=0.246)$. Likewise, those with mild to severe stunting were also more likely to be anaemic (36.9\%) compared to healthy ones (31.9\%). The difference also did not reach statistical significance $(p=0.156)$.

\section{Prevalence and intensities of malaria and soil- transmitted helminths in children}

Overall, 204 children (40.6\%) were infected with malaria parasites, among whom, $182(89.2 \%)$ were asymptomatic carriers and $22(10.8 \%)$ were symptomatic cases (axillary temperature $>37.5^{\circ} \mathrm{C}$ ). Plasmodium falciparum was the predominant species (96.6\%) with parasite density ranging from $0-792,000$ parasites $\mu$ l of blood. There was no significant difference in the prevalence and geometric mean parasite density in relation to sex of children and the area of residence; however, an age-related decrease in the geometric mean parasite density was observed (Table 2).

A total of 149 children (29.6\%) were infected with STHs. They included: 113 cases of $A$. lumbricoides (75.8\%), 79 cases of $T$. trichiura (53\%) and 45 cases of co-infections with both species (30.2\%). No infection with hookworm was detected. The prevalence of STHs was significantly higher in rural schoolchildren (40.6\%; $\mathrm{p}=0.000$ ) compared to those living in Mfou urban (20.8\%). However, geometric mean density of $T$. trichiura was significantly elevated in children from urban Mfou (mean=307 epg; $\mathrm{p}=0.039$ ) compared to rural school children (mean=130 epg). Children infected with $T$. trichiura had more than two fold increased chances of been underweight compared to uninfected ones $(\mathrm{OR}=2.33,95 \% \mathrm{Cl}: 1.25-4.36 ; \mathrm{p}=0.008)$. There was no significant association between the prevalence of anaemia and presence of STHs. However, children co-infected infected with malaria parasites and STHs showed increased 
Table 1. Prevalence of malnutrition and anaemia in relation to sex of children.

\begin{tabular}{|c|c|c|c|c|c|c|c|}
\hline \multirow{2}{*}{ Characteristic } & \multicolumn{2}{|r|}{ Male } & \multicolumn{2}{|r|}{ Female } & \multicolumn{2}{|c|}{ Total population } & \multirow[t]{2}{*}{ P-value } \\
\hline & $\mathbf{n}$ & Prevalence (\%) & $\mathbf{n}$ & Prevalence (\%) & $\mathbf{n}$ & Prevalence (\%) & \\
\hline \multicolumn{8}{|l|}{ Underweight category } \\
\hline Mild $(-1.01 \leq W A Z \geq-2)$ & 50 & 24.6 & 36 & 19.6 & 86 & 22.2 & 0.015 \\
\hline Moderate $(-2<W A Z \geq-3)$ & 9 & 4.4 & 0 & 0.0 & 9 & 2.3 & \\
\hline Severe $(-3<W A Z)$ & 1 & 0.5 & 1 & 0.5 & 2 & 0.5 & \\
\hline Normal (WAZz-1.0) & 143 & 70.4 & 147 & 79.9 & 290 & 74.9 & \\
\hline Total population & 203 & 52.5 & 184 & 47.5 & 387 & 100 & / \\
\hline \multicolumn{8}{|l|}{ Stunting category } \\
\hline Mild (-1.01 $\leq \mathrm{HAZ} \geq-2)$ & 68 & 25.3 & 42 & 17.9 & 110 & 21.9 & 0.051 \\
\hline Moderate $(-2<\mathrm{HAZ} \geq-3)$ & 21 & 7.8 & 17 & 7.3 & 38 & 7.6 & \\
\hline Severe $(-3<H A Z)$ & 8 & 3.0 & 2 & 0.9 & 10 & 2.0 & \\
\hline Normal (HAZ $\geq-1.0)$ & 172 & 63.9 & 173 & 79.3 & 345 & 68.6 & \\
\hline Total population & 269 & 53.5 & 234 & 46.5 & 503 & 100 & \\
\hline \multicolumn{8}{|l|}{ Anaemia status } \\
\hline Anaemia (hematocrit<33\%) & 88 & 32.7 & 80 & 34.3 & 168 & 33.5 & 0.701 \\
\hline${ }^{*}$ Mean hematocrit & 269 & $37.1 \pm 4.9$ & 233 & $36.8 \pm 4.7$ & 502 & $36.9 \pm 4.9$ & 0.544 \\
\hline
\end{tabular}

WAZ=Weight-for-age Z-scores; HAZ=Height-for-age Z-scores; WAZ indices were calculated for children aged 3-10 years, while HAZ indices were calculated for those aged 3-16 years; * values are arithmetic means \pm standard deviation.

Table 2. Prevalence of malaria and geo-helminths in relation to age of children.

\begin{tabular}{|c|c|c|c|c|c|}
\hline \multirow{2}{*}{ Characteristic } & \multicolumn{3}{|c|}{ Age category (years) } & \multirow{2}{*}{ Total population } & \multirow{2}{*}{$P$ value } \\
\hline & $3-4$ & $5-9$ & $10-16$ & & \\
\hline Total number of children surveyed & 45 & 290 & 168 & 503 & / \\
\hline Prevalence of malaria, \% (n) & $42.2(19)$ & 40.7 (118) & $39.9(67)$ & 40.6 (204) & 0.958 \\
\hline Light parasiteamia*, \% & 26.3 & 50.8 & 74.6 & 56.4 & \multirow{4}{*}{0.000} \\
\hline Moderate parasiteamia, \% & 42.1 & 33.1 & 19.4 & 29.4 & \\
\hline Heavy parasiteamia, \% & 10.5 & 15.3 & 4.5 & 11.3 & \\
\hline Very heavy parasiteamia, \% & 21.1 & 0.8 & 1.5 & 2.9 & \\
\hline Prevalence of STHs ${ }^{* *}, \%(n)$ & $15.6(7)$ & $23.8(69)$ & $43.5(73)$ & $29.6(149)$ & 0.000 \\
\hline
\end{tabular}


Table 2. Contd.

\begin{tabular}{|c|c|c|c|c|c|}
\hline Prevalence of Ascaris lumbricoides, \% & $13.3(6)$ & $18.6(54)$ & $31.5(53)$ & $22.5(113)$ & 0.002 \\
\hline Light density (1-4999 epg†), \% & 66.7 & 74.1 & 58.5 & 66.4 & \multirow{3}{*}{0.456} \\
\hline Moderate density (5000-49999 epg) , \% & 33.3 & 25.9 & 39.6 & 32.7 & \\
\hline Heavy density ( $\geq 50000 \mathrm{epg}), \%$ & 0.0 & 0.0 & 1.9 & 0.9 & \\
\hline Geometric mean parasite density, \% (epg) & $4301(1248-34464)$ & $1628(96-48192)$ & $2373(96,50496)$ & $2045(96,50496)$ & 0.307 \\
\hline Prevalence of Trichuris trichiura & $6.7(3)$ & $11.7(34)$ & $25.0(42)$ & $15.7(79)$ & 0.000 \\
\hline Light density (1-999 epg) & 100 & 79.4 & 83.3 & 82.3 & \multirow{3}{*}{0.647} \\
\hline Moderate density (1000-9999 epg) & 0.0 & 20.6 & 16.7 & 17.7 & \\
\hline Heavy density ( $\geq 10000$ epg) & 0.0 & 0.0 & 0.0 & 0.0 & \\
\hline Geometric mean parasite density (epg) & $76(48,96)$ & $191(24,3792)$ & $169(24,6408)$ & $173(24,6408)$ & 0.738 \\
\hline Prevalence of co-infections $\ddagger$ & $8.9(4)$ & $10.7(31)$ & $20.2(34)$ & $13.7(69)$ & 0.010 \\
\hline
\end{tabular}

${ }^{*}$ Classification of malaria parasiteamia: light parasiteamia (1-499 parasites/ $\mu \mathrm{l}$ of blood), moderate parasiteamia (500-1999 parasites/ $\mu \mathrm{l}$ of blood); heavy parasiteamia (2000-

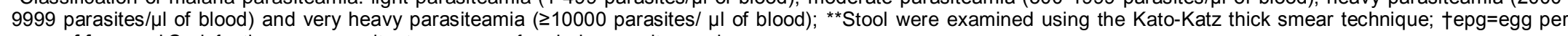
gram of faeces; $\ddagger$ Co-infections= concomitant presence of malaria parasites and worms eggs.

Table 3. Univariate and multivariate logistic regression analyses of the association between malaria infection and independent factors.

\begin{tabular}{|c|c|c|c|c|c|c|c|c|}
\hline Variable & & $\begin{array}{c}\text { Malaria positive } \\
(n=204)\end{array}$ & $\begin{array}{c}\text { Malaria negative } \\
(n=299)\end{array}$ & $\begin{array}{l}\text { Univariate analysis } \\
\left(\mathrm{OR}^{\star \star \star}, 95 \% \mathrm{Cl}\right)\end{array}$ & p-value & $\begin{array}{l}\text { Multivariate analysis } \\
\text { (Adjusted OR, 95\% Cl) }\end{array}$ & p-value & p-value for trend $\ddagger$ \\
\hline \multirow{2}{*}{ Fever* } & No & $182(39.3)$ & $281(60.7)$ & 1 & & & & \\
\hline & Yes & $22(55.0)$ & $18(45.0)$ & $1.88(0.98-3.61)$ & 0.056 & $1.80(0.86-3.78)$ & 0.118 & \\
\hline \multirow{2}{*}{ Anaemia** } & No & 195 (39.9) & $294(60.1)$ & 1 & & & & \\
\hline & Yes & 9 (69.2) & $4(30.8)$ & $3.38(2.29-4.97)$ & 0.000 & $2.64(1.71-4.07)$ & 0.000 & \\
\hline \multirow{3}{*}{$\begin{array}{l}\text { Underweight } \\
\text { categories† }\end{array}$} & Normal & $119(41.0)$ & $171(59.0)$ & 1 & & & & \\
\hline & Mild & $45(52.3)$ & $41(47.7)$ & $1.57(0.97-2.55)$ & 0.065 & $1.49(0.90-2.48)$ & 0.117 & \\
\hline & Moderate to severe & $1(9.1)$ & $10(90.9)$ & $0.14(0.01(1.13)$ & 0.066 & $0.13(0.01-1.12)$ & 0.064 & 0.046 \\
\hline \multirow{2}{*}{$\begin{array}{l}\text { Ascaris } \\
\text { lumbricoides }\end{array}$} & No & 148 (37.9) & $242(62.1)$ & 1 & & & & \\
\hline & Yes & $56(49.6)$ & $57(50.4)$ & $1.61(1.05-2.44)$ & 0.028 & $1.72(1.01-2.91)$ & 0.043 & \\
\hline
\end{tabular}

${ }^{*}$ Fever: Temperature $>37.5^{\circ} \mathrm{C}$, ${ }^{*}$ anaemia: Parked cell volume or hematocrit $<33 \%$, ${ }^{* * *}$ OR: Odds ratio; $†$ Mild underweight:-1.01SD $\leq W A Z$ score $\geq-2 S D$ and moderate to severe underweight: WAZ<-2 SD in children aged 3-10 years; SD: standard deviation; $\ddagger \mathrm{p}$-value for trend for $\mathrm{n}>2$ modalities.

increased chances of been anaemic, although this did not reach statistical significance (OR=1.64, $95 \% \mathrm{Cl}: 0.98-2.75 ; \mathrm{p}=0.059)$. But, mean level of haematocrit was significantly lower (mean $=35.4 \pm 4.7 \% ; \mathrm{p}=0.000$ ) in the latter compared to children with single Ascaris or Trichuris infections (mean $=39.7 \pm 4.1 \%$ ). Table 3 shows the prevalence and intensities of malaria and STHs in
relation
to
age
of children. 
infection, soil-transmitted helminths and undernutrition (underweight and stunting) in a total of 503 school children, aged 3-16 years, residing in Mfou health district, a forest area with perennial transmission of malaria, in Cameroon. Overall, malaria infection and soil-transmitted helminths $(A$. lumbricoides and $T$. trichiura) detected in these schoolchildren were associated with anaemia (malaria infection and to a certain extent malaria-helminth co-infections), undernutrition (underweight and stunting), and the area of residence (STHs).

The prevalence of malaria infection and STHs observed in these children are similar or lower compared to previous figures recorded in schoolchildren in Cameroon and elsewhere in Africa (Quakyi et al., 2000; Kimbi et al., 2005a, b; Egwunyenga and Ataikiru, 2005; Nkuo-Akenji et al., 2006; Achidi et al., 2008; Ayalew et al., 2011). In fact, in many areas where malaria infection and helminthiases are co-endemic, schoolchildren usually harbour the heaviest burden of the infections, with associated morbidity, especially when co-infected (Mwangi et al., 2006; Achidi et al., 2008). The survey was conducted at the beginning of the rainy season when malaria transmission was more likely to be elevated. However, over the past years, there have been some fluctuations in climate, often resulting in prolonged dry season periods in the study locality, as well as elsewhere in the country.

No significant difference was observed in the prevalence of malaria infection between rural schoolchildren and those residing in the urban area of Mfou; thus, suggesting probably a similar rate of transmission between the two localities. In fact, the environment in Mfou urban (an emerging semi-urban area) is closely related to that of Mfou rural, with stagnant water bodies, streams and swampy areas that are pre-sent year round and provide breeding sites for Anopheles mosquitoes. Factors significantly associated with increased risk of malaria infection included: Anaemia and infection with $A$. lumbricoides; while association with mild underweight did not reach statistical significance. In fact, association between malaria infection and anaemia is well recognized as malaria parasite, $P$. falciparum lives inside the red cell, and requires haemoglobin for its development. Thus, completion of the parasite life cycle is associated with the break-down of red blood cells leading to anaemia. However, the cause of anaemia has been shown to be multifactorial, and we found a significant low mean level of haematocrit in children co-infected with malaria parasites and STHs compared to those with a single helminth infection. It is also possible that in these children with prevalent undernutrition, low dietary intake in iron, or malabsorption of iron could also contribute to anaemia. In fact, increased prevalence of anaemia was observed in undernourished children (underweight and stunted), compared to normal children, however, the difference did not reach statistical significance.

Looking at the association between malaria infection and STHs, particularly, infection with $A$. lumbricoides, our data suggests increased susceptibility to asymptomatic malaria infection with concomitant Ascaris infection. In fact, there have been conflicting reports on the association between these two infections (Mwangi et al., 2006). Some studies conducted in patients with severe clinical forms of malaria (Nacher et al., 2002) or in schoolchildren (Murray et al., 1978) or children living in rural areas (Brutus et al., 2007) have suggested a protective effect of $A$. lumbricoides on malaria, while other studies have suggested a negative effect of this parasite or other worm infections on malaria (Spiegel et al., 2003; Sokhna et al., 2004; Le Hesran et al., 2004; Druilhe et al. 2005). As intensity of infection with $A$. lumbricoides seems to be important in this association as cited in these studies, we observed an increasing prevalence of malaria infection with increasing Ascaris load (moderate or heavy intensities), but this association was not statistically significant.

On the other hand, after adjusting for other factors, association between asymptomatic malaria infection and underweight (an indicator of both acute and chronic undernutrition) did not reach statistical significance $(p=0.117)$. In fact, mild underweight $(-1.01 \leq W A Z \geq-2 S D)$ was associated with increased risk of malaria infection $(p=0.065)$, while moderate to severe underweight (WAZ<2SD) was instead associated with a reduced risk of malaria infection $(p=0.066)$. However, the limited sample size of this latter category $(n=13)$ did not allow us to make an interpretation of the observations. Previous studies on the relationship between undernutrition and asymptomatic malaria have often lead to controversial findings. Some studies have shown a positive association while others did not. For example, in a study conducted in Equatorial Guinean children, stunting was positively related to malaria infection, while no significant association was found with wasting and underweight (Custodio et al., 2009). Additionally, in another study conducted in Ghanaian children, Crookston et al. (2010), found no significant association between chronic undernutrition and asymptomatic malaria detected by polymerase chain reaction (PCR).

However, it should be noted that most of these studies were conducted in children aged less than 5 years, while our study included children up to 16 years, as late school entrance is common in rural primary schools in Mfou. Other factors that could explain differences observed could be the level of transmission, the study design, including the diagnostic method used for malaria (microscopy or PCR), childrens' diets and also intercurrent infections.

Moreover, infection with STHs, particularly T. trichiura was significantly associated with increased risk of underweight, but this did not reach statistical significance after adjusting for area of residence and age of the children $(p=0.073)$. Previous studies have suggested that intestinal helminthiasis compromise healthy nutrition and growth in infected children. The variety of mechanisms 
used include reduced food intake due to malabsorption and/or reduced appetite, which result in higher levels of stunting (Stoltzfus et al., 1997; Stephenson et al., 2000; Crampton and Nesheim, 2002; Hotez et al., 2008; Hall et al., 2008; Brooker et al., 2010).

On the other hand, prevalence of STHs was significantly elevated in rural schoolchildren, with more than twofold increase in chance of being infected compared to children residing in urban Mfou. This is likely due to the sanitation conditions in rural areas where the majority of households do not have access to good potable water, and this offers the possibility for the spread and maintenance of these infections.

No infection with hookworm was detected in our study population and this is probably due to the low prevalence in the study area based on statistics of the clinical laboratory of Mfou district hospital, which is the referral hospital in the district. This could also be related to the fact that the Kato-Katz slides were not read immediately after preparation. It is likely that hookworm eggs deteriorate during the 15-24 $\mathrm{h}$ incubation period before slides reading. This likely lead to underestimation, as it has been suggested that hookworm eggs collapsed and disappeared shortly after the thick smear had cleared (Santos et al., 2005).

On the other hand, mild to severe underweight (WAZs1.01SD) was significantly associated with the area of residence, sex and age of children. A sex-related increase in the prevalence of undernutrition was observed, with boys significantly more likely to be underweight or stunted, than girls. This observation has already been noted in previous studies (Stoltzfus et al., 1997; Genton et al., 1998; Wamani et al., 2007); and it has been suggested that the daily energy and micronutrients intakes of the study population could be different by sex. Also, malaria infection and geo-helminths could act as cofounders in this association, but we did not find any sex-related association with these two infections.

\section{Conclusion}

The cross-sectional nature of our study limits the interpretation of some of the observations, but the data provide additional support to the fact that malaria infection and STHs exacerbate anaemia and undernutrition in schoolchildren of the study locality. Also, concomitant Ascaris infection increases the risk of malaria infection in these schoolchildren. Thus, current preventive strategies including use of long lasting insecticide treated bed nets in households and annual school-based deworming programs coupled with a nutritional component should be reinforced in this age group.

\section{ACKNOWLEDGEMENTS}

We thank the primary school children of Mfou for their participation, the teachers and local education authorities for their support and commitment during the study. The study was supported by European Foundation Initiative for Neglected Tropical Diseases (NTDs) "EFINTD" through a Travel grant $\left(\mathrm{N}^{\circ}\right.$ I/83 999) offered to $\mathrm{Dr}$ Tchinda.

\section{REFERENCES}

Achidi EA, Apinjoh TO, Mbunwe E, Besingi R, Yafi C, Wenjighe AN, Ajua A, Anchang JK (2008). Febrile status, malarial parasitaemia and gastro-intestinal helminthiases in schoolchildren resident at different altitudes, in South-western Cameroon. Ann. Trop. Med. Parasitol. 102:103-118.

Ayalew A, Debebe T, Worku A (2011). Prevalence and risk factors of intestinal parasites among Delgi school children, North Gondar, Ethiopia. J. Parasitol. Vector Biol. 3(5):75-81.

Bethony JR, Brooker S, Albonico M, Geiger M, Loukas A, Diemert D, Hotez PJ (2006). Soil-transmitted helminth infections: ascariasis, trichuriasis, and hookworm. Lancet 367:1521-1532.

Brooker R (2010). Estimating the global distribution and disease burden of intestinal nematode infections: Adding up the numbers - A review. Int. J. Parasitol. 40(10):1137-1144.

Brooker S, Akhwale W, Pullan R, Estambale B, Clarke SE, Snow RW, Hotez PJ (2007). Epidemiology of Plasmodium-Helminth co-infection in Africa: Populations at risk, potential impact on anemia, and prospects for combining control. Am. J. Trop. Med. Hyg. 77(6):88-98.

Brooker S, Donnelly CA, Guyatt HL (2000). Estimating the number of helminthic infections in the Republic of Cameroon from data on infection prevalence in schoolchildren. Bull. WHO 78:1456-1465.

Brutus L, Watier L, Hanitrasoamampionona V, Razanatsoarilala H, Cot M (2007). Confirmation of the Protective Effect of Ascaris lumbricoides on Plasmodium falciparum Infection: Results of a Randomized Trial in Madagascar. Am. J. Trop. Med. Hyg. 77:10911095.

Caulfield LE, Richard SA, Black RE (2004). Undernutrition as an underlying cause of malaria morbidity and mortality in children less than five years old. Am. J. Trop. Med. Hyg. 71:55-63.

Crompton DWT, Nesheim MC (2002). Nutritional impact of intestinal helminthiasis during the human life cycle. Annu. Rev. Nutr. 22:35-59.

Crookston BT, Alder SC, Boakye I, Merrill RM, Amuasi JH, Porucznik CA, Stanford JB, Dickerson TT, Dearden KA, Hale DC, Sylverken J, Snow BS, Osei-Akoto A, Ansong D (2010). Exploring the relationship between chronic undernutrition and asymptomatic malaria in Ghanaian children. Malar. J. 9:39.

Custodio E, Descalzo MÁ, Villamor E, Molina L, Sánchez I, Lwanga M, Bernis C, Benito A, Roche J (2009). Nutritional and socio-economic factors associated with Plasmodium falciparum infection in children from Equatorial Guinea: results from a nationally representative survey. Malar. J. 8:225.

District health Management Team (2011). Mfou Health District Management Plan for the year 2011. $40 \mathrm{p}$ (in French).

Druilhe P, Tall A, Sokhna C (2005). Worms can worsen malaria: towards a new means to roll back malaria? Trends Parasitol. 21:359362.

Egwunyenga AO, Ataikiru PD (2005). Soil-transmitted helminthiasis among school age children in Ethiope East local government area, Delta state, Nigeria. Afr. J. Biotechnol. 4(9):938-941.

Genton B, Al-Yaman F, Ginny M, Taraika J, Alpers MP (1998). Relation of anthropometry to malaria morbidity and immunity in Papua New Guinean children. Am. J. Clin. Nutr. 68:734-741.

Hall A, Hewitt G, Tuffrey V, de Silva N (2008). A review and metaanalysis of the impact of intestinal worms on child growth and nutrition. Matern. Child Nutr. 4(1):118-236.

Hotez PJ, Brindley PJ, Bethony JM, King CH, Pearce EJ, Jacobson J (2008). Helminth infections: the great neglected tropical diseases. J. Clin. Investig. 118: 1311-1321.

Kimbi HK, Awah NW, Ndamukong KJ, Mbuh JV (2005b). Malaria infection and its consequences in school children. East Afr. Med. 
J. 82: 92-97.

Kimbi HK, Nformi D, Ndamukong KJ (2005a). Prevalence of asymptomatic malaria among school children in an urban and rural area in the Mount Cameroon region. Cent. Afr. J. Med. 51(1-2):5-10.

Le Hesran JY, Akiana J, Ndiaye EH, Dia M, Senghor P, Konate L (2004). Severe malaria attack is associated with high prevalence of Ascaris lumbricoides infection among children in rural Senegal. Trans. R. Soc. Trop. Med. Hyg. 98:397-399.

Leke RGF, Bigoga JD, Zhou J, Fouda GG, Leke RJI, Tchinda V, Megnekou R, Fogako J, Sama G, Gwanmesia P, Bomback G, Nama C, Diouf A, Bobbili N, Taylor DW (2010). Longitudinal studies of Plasmodium falciparum malaria in pregnant women living in a rural Cameroonian village with high perennial transmission. Am. J. Trop. Med. Hyg. 83(5):996-1004.

Mfonkeu PJB, Gouado I, Kuate HF, Zambou O, Combes V, Grau GER, Amvam Zollo PH (2010). Biochemical markers of nutritional status and childhood malaria severity in Cameroon. Br. J. Nutr. 104:886892.

Ministry of Public Health, Cameroon/National Malaria Control Programme (2011). Report of activities of the NMCP for the year 2010 (in French).

Mupfasoni D, Karibushi B, Koukounari A, Ruberanziza E, Kaberuka T, Kramer MH, Mukabayire O, Kabera M, Nizeyimana V, Deville MA, Ruxin J, Webster JP, Fenwick A (2009). Polyparasite Helminth Infections and Their Association to Anaemia and Undernutrition in Northern Rwanda. PLoS Negl. Trop. Dis. 3(9):e517.

Murray J, Murray A, Murray M, Murray C (1978). The biological suppression of malaria: an ecological and nutritional interrelationship of a host and two parasites. Am. J. Clin. Nutr. 31(8):1363-1366.

Mwangi TW, Bethony J, Brooker S (2006). Malaria and helminth interactions in humans: an epidemiological viewpoint. Ann. Trop. Med. Parasitol. 100(7):551-570.

Nacher M, Singhasivanon P, Traore B, Vannaphan S, Gay F, Chindanond D, Franetich JF, Mazier D, Looareesuwan S (2002). Helminth infections are associated with protection from cerebral malaria and increased nitrogen derivatives concentrations in Thailand. Am. J. Trop. Med. Hyg. 66:304-309.

Nkuo-Akenji TK, Chi PC, Cho JF, Ndamukong KK, Sumbele I (2006). Malaria and helminth co-infection in children living in a malaria endemic setting of mount Cameroon and predictors of anemia. J. parasitol. 92(6):1191-1195.

Quakyi IA, Leke RGF, Befidi-Mengue R, Tsafack M, Bomba-Nkolo D, Manga L, Tchinda V, Njeungue $E$, Kouontchou S, Fogako J, Nyonglema P, Harun LT, Djokam R, Sama G, Eno A, Megnekou R, Metenou S, Ndoutse L, Same-Ekobo A, Alake G, Meli J, Ngu J, Tietche F, Lohoue J, Mvondo JL, Wansi E, Leke R, Folefack A, Bigoga J, Bomba-Nkolo C, Titanji V, Walker-Abbey A, Hickey MA, Johnson AH, Taylor DW (2000). The epidemiology of Plasmodium falciparum malaria in two Cameroonian villages: Simbok and Etoa. Am. J. Trop. Med. Hyg. 63(5,6):222-230 .
Santos FLN, Cerqueira EJL, Soares NM (2005). Comparison of the thick smear and Kato-Katz techniques for diagnosis of intestinal helminth infections. Rev. Soc. Bras. Med. Trop. 38(2):196-198.

Snow RW, Guerra CA, Noor AM, Myint HY, Hay SI (2005). The global distribution of clinical episodes of Plasmodium falciparum malaria. Nat. 434:214-217.

Sokhna C, Le Hesran JY, Mbaye PA, Akiana J, Camara P, Diop M, Ly A, Druilhe $P$ (2004). Increase of malaria attacks among children presenting concomitant infection by Schistosoma mansoni in Senegal. Malar. J. 3:43.

Spiegel A, Tall A, Raphenon G, Trape JF, Druilhe P (2003). Increased frequency of malaria attacks in subjects co-infected by intestinal worms and Plasmodium falciparum malaria. Trans. R. Soc. Trop. Med. Hyg. 97: 198-199.

Stephenson LS, Latham MC, Ottesen EA (2000). Malnutrition and parasitic helminth infection. Parasitol. 121:S23-S38.

Stoltzfus R, Albonico M, Tielsch J, Chwaya HM, Savioli L (1997). Linear growth retardation in Zanzibari school children. J. Nutr. 127:10991105.

Tchuem TLA, Behnke JM, Gilbert F, Southgate VR, Vercruysse J (2003). Polyparasitism with Schistosoma haematobium and soiltransmitted helminth infections among school children in Loum, Cameroon. Trop. Med. Int. Health 8:975-986.

Tchuem TLA, N'Goran EK (2009). Schistosomiasis and soil-transmitted helminthiasis control in Cameroon and Côte d'Ivoire: Implementing control on a limited budget. Parasitol. 136:1-7.

Wamani H, Astrom AN, Peterson S, Tumwine JK, Tylleskar T (2007). Boys are more stunted than girls in sub-Saharan Africa: a metaanalysis of 16 demographic and health surveys. BMC Pediatr. 7:17.

World Health Organisation (1983). Measuring Change in Nutritional Status. Guidelines for Assessing the Nutritional Impact of Supplementary Feeding programmes for Vulnerable Groups. WHO, Geneva. 102 p.

Ziegelbauer K, Speich B, Mäusezahl D, Bos R, Keiser J, Utzinger J (2012). Effect of sanitation on soil-transmitted helminth infection: Systematic review and meta-analysis. PLoS Med. 9(1):e1001162. 